\title{
Correction to: A multicenter study on epidemiological and clinical characteristics of 125 newborns born to women infected with COVID-19 by Turkish Neonatal Society
}

Mehmet Yekta Oncel ${ }^{1,2}$ (D) Ilke Mungan Akın ${ }^{3} \cdot$ Mehmet Kenan Kanburoglu ${ }^{4} \cdot$ Cuneyt Tayman $^{5} \cdot$ Senay Coskun $^{6}$. Fatma Narter ${ }^{7}$. Ilkay $\mathrm{Er}^{8}$ - Tinatin Gelenava Oncan ${ }^{9}$ - Asli Memisoglu ${ }^{10} \cdot$ Merih Cetinkaya $^{11} \cdot$ Demet Oguz $^{12}$. Omer Erdeve ${ }^{13} \cdot$ Esin Koc $^{14}$ on behalf of the Neo-Covid Study Group

Published online: 22 August 2020

(C) Springer-Verlag GmbH Germany, part of Springer Nature 2020

\section{Correction to: European Journal of Pediatrics} https://doi.org/10.1007/s00431-020-03767-5

The publisher regrets that the "The Neo-Covid StudyGroup" list of collaborators were not uploaded during processing of the original version of the above published article. The original article has been corrected.

Publisher's note Springer Nature remains neutral with regard to jurisdictional claims in published maps and institutional affiliations.

The online version of the original article can be found at https://doi.org/ $10.1007 / \mathrm{s} 00431-020-03767-5$

Mehmet Yekta Oncel

dryekta@gmail.com

Ilke Mungan Akın

ilkemungan@gmail.com

Mehmet Kenan Kanburoglu

kanburoglumk@outlook.com

Cuneyt Tayman

ctayman22@gmail.com

Senay Coskun

coskunsenay@yahoo.com

Fatma Narter

fatmakaya06@yahoo.com.tr

Ilkay Er

ilkayer7778@yahoo.com
Tinatin Gelenava Oncan

tgelenava@yahoo.com

Asli Memisoglu

acinarmemisoglu@gmail.com

Merih Cetinkaya

drmerih@yahoo.com

Demet Oguz

demoguz@hotmail.com

Omer Erdeve

omererdeve@yahoo.com

Esin Koc

esinkoc@gazi.edu.tr

Extended author information available on the last page of the article 


\section{Affiliations}

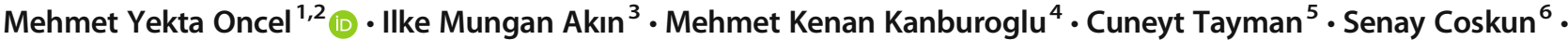 Fatma Narter ${ }^{7}$. Ilkay $\mathrm{Er}^{8} \cdot$ Tinatin Gelenava Oncan $^{9} \cdot$ Asli Memisoglu ${ }^{10} \cdot$ Merih Cetinkaya $^{11} \cdot$ Demet Oguz $^{12}$. Omer Erdeve ${ }^{13} \cdot$ Esin Koc $^{14} \cdot$ on behalf of the Neo-Covid Study Group}

1 Department of Pediatrics, Division of Neonatology, School of Medicine, İzmir Katip Çelebi University, İzmir, Turkey

2 Division of Neonatology, Tepecik Training and Research Hospital, University of Health Sciences, Konak, 35180 İzmir, Turkey

3 Division ofNeonatology,Umraniye Training and ResearchHospital, University of Health Sciences, İstanbul, Turkey

4 Department of Pediatrics, Division of Neonatology, School of Medicine, Rize Recep Tayyip Erdoğan University, Rize, Turkey

5 Division of Neonatology, Ankara City Hospital, Ministry of Health, Ankara, Turkey

6 Division of Neonatology, Sancaktepe Training and Research Hospital, University of Health Sciences, İstanbul, Turkey

7 Division of Neonatology, Kartal Dr. Lütfi Kırdar City Hospital, Ministry of Health, İstanbul, Turkey
8 Division of Neonatology, Kocaeli Derince Training and Research Hospital, University of Health Sciences, Kocaeli, Turkey

9 Division of Neonatology, Bornova Türkan Özilhan State Hospital, Ministry of Health, İzmir, Turkey

10 Department of Pediatrics, Division of Neonatology, School of Medicine, Marmara University, İstanbul, Turkey

11 Division of Neonatology, Kanuni Sultan Süleyman Training and Research Hospital, University of Health Sciences, İstanbul, Turkey

12 Division of Neonatology, Haseki Training and Research Hospital, Ministry of Health, İstanbul, Turkey

13 Department of Pediatrics, Division of Neonatology, School of Medicine, Ankara University, Ankara, Turkey

14 Department of Pediatrics, Division of Neonatology, School of Medicine, Gazi University, Ankara, Turkey 